\section{SITUATION OF SEXUAL AND GENDER BASED VIOLENCE AMONG THE ROHINGYA MIGRANTS RESIDING IN BANGLADESH}

${ }^{1}$ Farzana Islam, ${ }^{2}$ Mohiuddin Hussain Khan, ${ }^{2}$ Masako Ueda, ${ }^{3} \mathrm{NM}$ Robiul Awal Chowdhury, ${ }^{1}$ Salim Mahmud Chowdhury, ${ }^{2}$ Mshauri David Delem, ${ }^{1}$ Aminur Rahman. ${ }^{1}$ Centre for Injury Prevention and Research, Bangladesh (CIPRB); ${ }^{2}$ International Organisation for Migration (IOM): ${ }^{3}$ Department of Anthropology, Comilla University, Bangladesh

\subsection{6/injuryprev-2016-042156.724}

Background Since the late 1970's, Cox's Bazar district of Bangladesh had an influx of Rohingya refugees from Myanmar in different phases. Cox's Bazar is currently hosting 200,000-500,000 undocumented Myanmar nationals (UMNs), either in cluster settlements or within the host community. The migrants have placed an extra burden on the existing health, water, sanitation and social services. Anecdotal information suggests that women and adolescent girls are at increased risk of domestic violence and sexual abuse. A study was carried out to explore the situation of sexual and gender based violence and the level of awareness about the available support services among the Rohingya migrants.

Methods A qualitative study was carried out in 2015 to explore sexual and gender based violence and context where UMNs live and how social norms, ethnicity, power or politics influence the situation. Eight FGDs with men, women,adolescent boys and girls were conducted. The interviews were audio-taped and transcribed. ATLAS ti software was used and thematic analysis was done.

Results The respondents reported that domestic violence (beating wives) was the most common form of violence. They added that there was always a "tension" between the Rohingyas and the host community, and the Bengalis always teased, threatened and sometimes assaulted them physically. The women and adolescent-girl respondents narrated that they were often teased or sexually harassed by the host community men particularly during collecting water from a distant location. The UMN respondents complained they did not get any justice from the local administration when they became victims of violence. It was revealed that the both male and female respondents were not much aware about the support service available for sexual and gender based violence. Conclusions The study revealed that the UMNs particularly females were the victims of sexual and gender based violence and they were not aware of the available support services.

\section{DOMESTIC VIOLENCE AND RISK FACTORS AMONG RURAL AND URBAN PREGNANT WOMEN IN NIGER- DELTA, NIGERIA}

${ }^{1}$ Omolara Tella, ${ }^{2}$ Charles Tobin-west, ${ }^{2}$ Seye Babatunde. 'Department of Community Medicine, University of Port Harcourt Teaching Hospital; ${ }^{2}$ Department of Preventive and Social Medicine, University of Port Harcourt

\subsection{6/injuryprev-2016-042156.725}

Background Domestic Violence in pregnancy is an issue of immense public health concern. The prevalence is high in low and middle income countries with marked variations within and among such nations.

Methods A cross-sectional comparative study design was used and participants were selected using a multistage sampling technique. Data analysis was carried out using SPSS with p-value of 0.05 .
Results The commonest form of DV reported was psychological violence $66.8 \%$ (rural $69.3 \%$ and urban 64.4\%). The least reported form of DV was sexual violence $11.3 \%$ (rural $14.2 \%$ and urban $8.5 \%$ ). Verbal violence was $47.9 \%$ (rural $46.2 \%$ and urban $49.6 \%$ ) and physical violence was $33.4 \%$ (rural $43.6 \%$ and urban $23.4 \%$ ). Intimate partners formed the highest proportion of perpetrators of DV for both groups (rural 59.0\% and urban 48.7\%). The risk factors identified were geographic location that is residing in a rural area (AOR 2.052 95\% C.I: 1.349 - 3.122). Other significant findings on bi-variate analysis were alcohol use by victims; alcohol and other substance abuse and controlling behaviour by intimate partners. Intimate partners of the professionals' category were less likely to perpetrate physical violence in the rural group. Approximately half (46.7\%) of the rural group and $38.9 \%$ of the urban group sought for help following incidents of DV. Help was mainly sought from informal sources such as family and friends interventions (rural 42.7\% and urban $32.7 \%$ ). Very few women (rural $1.3 \%$ and urban $2.5 \%$ ) sought for formal help from the police. Coping strategies employed were mainly 'keeping silent' (rural 52.9\% and urban 36.0\%), 'reporting to family and friends' (rural 11.1\% and urban16.9\%) and 'staying away from perpetrators' (rural 2.2\% and urban $3.8 \%)$.

Conclusions This study confirmed that the prevalence of DV against pregnant women was high among pregnant women in rural and urban areas of Rivers state and that victims rarely used formal help-seeking resources.

\section{INTIMATE PARTNER VIOLENCE AND HEALTH LITERACY IN ZAMBIA}

${ }^{1,2}$ Sarah Schrauben, ${ }^{3}$ Gotsang Garechaba, ${ }^{2}$ Douglas Wiebe. ${ }^{1}$ Hospital of the University of Pennsylvania, USA; ${ }^{2}$ Center for Clinical Epidemiology and Biostatistics, University of Pennsylvania, USA; ${ }^{3}$ Sbrana Psychiatric Hospital, Ministry of Health, Botswana

\subsection{6/injuryprev-2016-042156.726}

Background Intimate partner violence (IPV) is a worldwide public health problem, especially in low- and middle-income countries. Increasingly, there is research investigating whether health literacy may be protective against certain health problems. We investigated whether health literacy may be protective against IPV, using Zambia as a case study.

Methods We accessed data for Zambia collected through the 2007 Demographic and Health Surveys Program administered by the United States Agency for International Development. We derived a dichotomous measure of health literacy that we have reported previously. Responses to questions regarding verbal, physical, and sexual abuse were used to derive a dichotomous outcome variable representing a history of any IPV. A second measure represented whether victims of IPV had ever sought help. Multivariate logistic regression was used to test the hypothesis that having high health literacy would be protective against IPV.

Results 4,229 respondents between the ages of 15-49 years participated in the survey. $54.1 \%$ had experienced some type of IPV and $17.2 \%$ of those had sought help. $24.3 \%$ had high health literacy. The odds of IPV were higher among: 20-29 year-olds $(\mathrm{OR}=1.7,95 \% \mathrm{CI}:=1.3,2.3)$ and $30-39$ year-olds $(\mathrm{OR}=1.5,95 \% \mathrm{CI}:=1.1,2.0)$, women with less than secondary education $(\mathrm{OR}=1.5,95 \% \mathrm{CI}:=1.1,2.2)$, formerly married women $(\mathrm{OR}=1.7,95 \% \mathrm{CI}:=1.4,2.1)$, women living in urban areas $(\mathrm{OR}=1.5,95 \% \mathrm{CI}:=1.1,2.0)$, and did not vary by level of income. After controlling for these characteristics, 
women with high health literacy were $19 \%$ less likely to have ever experienced IPV $(\mathrm{OR}=0.81,95 \% \mathrm{CI}:=0.6,1.0)$. Health literacy and seeking help were not related.

Conclusions This is the first study to find that high health literacy as measured with a robust indicator in a large national sample was protective against IPV. Opportunities should be identified to improve health literacy in an attempt to prevent this global health problem.

\section{Disabled Persons and Safety}

\section{Post Tue 2.12}

\section{MOBILITY RELATED INJURY AMONG LEARNERS WITH VISUAL IMPAIRMENT AT THE UNIVERSITY OF JOS NIGERIA}

'Samuel Olawuwo, ${ }^{2}$ Alphonsus Yakubu, ${ }^{3}$ Suraju Rasaki, ${ }^{4}$ Sylvester Yakwal. 'Physical Therapist, Department of Special Education and Rehabilitation Sciences, University of Jos Nigeria; 2Department of Special Education and Rehabilitation Sciences, University of Jos Nigeria; ${ }^{3}$ Universal Basic Education Board (Special Need Education Unit), Garki Abuja; ${ }^{4}$ Department of Special Education and Rehabilitation Sciences, University of Jos Nigeria

10.1136/injuryprev-2016-042156.727

Background Vision is not a requirement for independent mobility. Students with visual impairment faces more challenges in their studies compared with sighted peers as a result of gap in speed, volume and distance of obtaining information which cannot be adequately quantified resulting in mobility related injury such as head-level, strips and fall.

Method Thirty undergraduates with visual impairments were surveyed and interviewed on frequency, nature and causes of headlevel and fall injuries they encountered at the university. Mobility related injury questionnaire was administered using purposive sampling technique. The questionnaire has four themes: demographical information, travel habits, head-level accidents and trip/ fall accidents. Data were computed with SPSS version 20.

Results 73.3 percent of the participants were male while 26.7 percent were female. 80 percent of the respondents stated that they use mobility aids, out of which 66.7 percent are cane and sighted guide users. $22(73.3 \%)$ of respondents reported to have prior knowledge of orientation and mobility, while 10 (33.3\%) has not receive lecture in orientation and mobility since their enrolment at the institution. Majority of the participants has encountered head-level injury with $22(73.3 \%)$ and $8(26.7 \%)$ affirmed that the injury is with medical consequences and bed rest respectively. 28 (93.3\%) of trip and fall had resulted in person with visual impairment changing their walking strategy and 53.3 percent claimed that their confidence as an independent traveller is not affected by the fall. There is a significant association between independent traveller confidence and having the opportunity to have received lectures in O\& $\mathrm{M}$ since enrolled at the university $(\mathrm{r}=-0.189, \infty=0.5)$.

Conclusion The interview enabled us to see the risk involve in independent mobility experienced by students with various degree of vision loss. Head level injury and fall which learners experience more often needs to be addressed by the school authority.

\section{HEALTH AWARENESS \& LIFE SKILLS EDUCATION IMPACT ON CHILDREN WITH DISABILITY FROM LOW- INCOME HOUSEHOLDS}

${ }^{1}$ Aditi Kamat, ${ }^{2}$ Manohari Kamat. ${ }^{1}$ HARI OM NGO, Belgaum India; ${ }^{2}$ HARI OM NGO, Belgaum India

10.1136/injuryprev-2016-042156.728

Background According to UN Enable, around 10\% of the world's populations, 650 million people, live with disabilities. Census 2001 has revealed that over 21 million people in India as suffering from one or the other kind of disability. This is equivalent to $2.1 \%$ of the population. Among the total disabled in the country, 12.6 million are males and 9.3 million are females. Even though current disability figures are not the most reliable, it is noteworthy that national prevalence rates suggest that about 35 percent of people with disabilities are in the 10-29 years age group.

Methods The stratified sampling study was conducted in the southern district Belgaum in India within seven years from Sep 2008 to Sep 2014 and covered the population of all disabled children from low income rural set ups.

Results Nearly 60 percent of the children who underwent health awareness and life skills education showed significant improvement in over all growth and wellbeing. About 60 percent of this group completed their primary education, and 10 percent went on to continue high school. Their overall health improved leading to improved personal development. This resulted in their active participation in school and society.

Conclusions Early health awareness can help in the building of self esteem, betterment of health and reduce infections and cases school dropouts.

\section{Epidemiology}

\section{Post Tue 2.13}

\section{FEASIBILITY ASSESSMENT OF INTEGRATED ROAD TRAFFIC CASUALTIES REGISTRY IN WEST BANK, PALESTINE}

Mohammad Baniode, Oleg Storozhenkho, Rand Salman. Palestinian National Institute of Public HealthMorld Health Organisation (WHO), Occupied Palestinian Territory, Palestine

\subsection{6/injuryprev-2016-042156.729}

Background Road traffic casualties and risks are poorly quantified in the West Bank, Palestine. The aim of this study was to provide a first-ever overview of road traffic casualties (RTC) surveillance systems, and to assess the feasibility of establishing an integrated RTC registry in West Bank to provide reliable data to decision makers.

Methods General assessment methodology for surveillance systems and registries (World Health Organisation and CDC, USA) were used. The assessment took place in 2014 in collaboration with the Palestinian Ministry of Health $(\mathrm{MoH})$ and Ministry of Interior. Qualitative methods were used, including semi-structured questionnaires, in-depth interviews and review of grey literature. 